\title{
Social Stratification and Leisure Consumption: Empirical Evidence Based on Micro Survey Statistics in China
}

\author{
Hailiang Yao \\ Central University of Finance and Economics, Beijing, China \\ Email: yaohailiang83@126.com
}

How to cite this paper: Yao, H.L. (2020) Social Stratification and Leisure Consumption: Empirical Evidence Based on Micro Survey Statistics in China. Open Journal of Business and Management, 8, 346-356. https://doi.org/10.4236/ojbm.2020.81021

Received: December 18, 2019

Accepted: January 13, 2020

Published: January 16, 2020

Copyright ( 2020 by author(s) and Scientific Research Publishing Inc. This work is licensed under the Creative Commons Attribution International License (CC BY 4.0).

http://creativecommons.org/licenses/by/4.0/

\section{(c) (i) Open Access}

\begin{abstract}
This paper empirically analyzes the impact of social stratification of Chinese residents on leisure consumption. Based on the data from 2016 Chinese Family Panel Studies (CFPS), the regression results of instrumental variables show that the social level of Chinese residents has a significant positive impact on leisure consumption, considering the endogenous possibility of social stratification on leisure consumption. The policy implication of this paper is that when launching policies related to the cultural industry and leisure consumption, responsible departments of Chinese government should fully consider the possibility and complexity of the influence of Social stratification on the effectiveness of policies.
\end{abstract}

\section{Keywords}

Social Class, Leisure Consumption, Chinese Household

\section{Introduction}

With the rapid economic growth and all-round social development in China, the income level of urban and rural residents in China has continued to improve, and residents pay more and more attention to the improvement and enhancement of their well-being. Leisure consumption refers to a higher-level consumption demand after one's basic living needs are met. Leisure consumption usually includes cultural and entertainment supplies, visits to exhibitions, fitness activities, group travel, and other recreational activities. Leisure consumption has a direct impact on the improvement of living qualities from the aspects of humanity, culture, sociality, creativity and so on, all related to the complete, comprehensive and healthy development of oneself. Meanwhile, leisure consumption 
can also create and drive the growth and development of a series of cultural industries, which plays a significant role in promoting the economic development and social progress.

According to the neoclassical economic theory, decision-making in individual consumption is mainly determined by economic factors such as consumer incomes, budget constraints and relative price of commodities. Individual consumers can list their preferences and comprehensively observe the market situation. Leisure consumption, on the other hand, is a type of "experience product". Although the influence of economic factors on leisure consumption basically conforms to the general economic rules, in many cases, there are also some particularities in many cases. Whether individual consumers prefer leisure products or not is quite subjective or even subtle, and their consumption contents and forms are more likely to reflect their life attitudes and ways of living. Compared with the rigid demand for general commodities, leisure consumption is usually elastic. According to the hypothesis of increasing marginal utility based on the accumulation of personal cultural capitals put forward by Throsby [1], with the increase of individual consumers' experience of leisure consumption, the understanding and appreciation ability of consumers themselves to consumption objects will also be improved, and more leisure consumption is likely to be conducted in the future.

Based on the hypothesis of consumer heterogeneity, in addition to income and other economic characteristics, some references have set off from the possible impact of people's different social-demographic characteristics on leisure consumption from a micro perspective [2] [3] [4]. These characteristics mainly include ages, genders, incomes, education backgrounds and marital statuses and physical condition. These empirical studies found that the above heterogeneity features have indeed significantly influenced leisure consumption. Summing up the above literature on the influential factors of leisure consumption, it can be found that although some studies have taken a micro perspective to analyze the influencing factors of people's leisure consumption from the characteristics of individual heterogeneity, a highly essential factor is often ignored in many micro factors: the Social stratification of residents.

Social level refers to the generally accepted ranking of individuals or groups in society [5]. The social level is usually the concept of a group. Each member of the group may have a different ranking in the simple ranking, but they also enjoy the social level obtained as a member of the group. At the same time, they need to constrain the members of the group together, control the entry of new members to shape or maintain the image and authority of this group in society [6]. Social and economic status of an individual or group can be measured as a blend of wealth, income, occupation, and education. Other contributors to social and economic status include race, ethnicity, home ownership, family size, family types, and even types of foods purchased. The combination of social and economic status can reveal a group or individual's unequal access to resources, privilege, power, and control in a society [7]. Previous studies have indicated that 
the social rank regulates social behaviors and emotion in a variety of species, whereby individual organisms live within the framework of their ranks [8].

From the possible influence mechanism of social class on leisure consumption, the level of social class is reflected in the amount of spare time, economic resources and political resources occupied by individuals. Even if the social class does not directly enter the utility function, the higher social class can enjoy more social resources without allocated in the market [9] [10]. People of higher social class may have more consumption categories and flexibility [11]. According to the theory of self-classification, compared with groups with lower social status, groups with higher social status are more likely to consider social status as an important attribute of self-classification. The improvement of social status is usually accompanied by the rising demand for consumption, that is "own more, want more" [12]. In addition, in order to further meet the diversified consumption demand, the higher social class tends to live in areas with more abundant product supply, which further promotes leisure consumption from the supply side. According to the network external theory of Rauch \& Scoppa [13], the consumption decisions of individuals or group consumers with similar Social stratification may be more mutually influenced. Through the above process or the influence mechanism, the social "gradient" in leisure consumption can be reflected in practice, that is, the higher the social class of residents, the more likely they are to own more consumption categories and consumption flexibility, and the higher the leisure consumption results from the external characteristics of it.

There is a lack of current research related to the influence of social class on leisure consumption inside and outside China. Although some researches emphasize that social class has an impact on leisure consumption, there is a lack of case studies and empirical evidence on this in the literature, especially evidence from micro statistics. To fill in the gaps of the references, this paper applies the data of Chinese Family Panel Studies (CFPS) in 2016 to empirically analyze the impact of social class on Chinese leisure consumption from a micro perspective. Based on the 2016 CFPS questionnaire, we chose the local social status of residents as the explanatory variable to reflect their social class. At the same time, taking into account the possible impact on residents' leisure consumption from demographic and economic characteristics [14] [15], such as genders, ages, marital statuses, and health conditions to explore the impact of Chinese residents' social class on leisure consumption. Meanwhile, considering the demographic and economic characteristics, the possibility of affecting residents "leisure consumption, we include residents" gender, age, and marital status in the regression analysis, Health status, income, assets, and other demographic variables. In the regression analysis, we include demographic variables such as gender, age, marital status, health status, income, assets. In addition, we will not only control the influence of population characteristics on leisure consumption in the regression, but also consider the endogenous possibility of social class affected by leisure consumption. Moreover, we will also discuss the influence of social class on other consumption items of the family and the influence of population characteris- 
tics on leisure consumption.

The possible contribution of this article is to take Chinese families as a sample and explain the leisure consumption by introducing the social level of residents. For the first time, the specific impact of the social level of Chinese residents on leisure consumption is systematically examined. Considering the possibility of endogenous leisure consumption at the social level, this paper constructs an instrumental variable measurement model to test and deal with the endogenous potential of the social level. According to the regression results, we can draw the conclusion that the social level has a significant positive impact on leisure consumption, and obtained solid and credible supporting evidence. We may not only improve the existing empirical research based on Chinese families, but also provide a new aspect to explain Chinese leisure consumption behavior, which works as a reference for the promotion of Chinese culture industry. Furthermore, by focusing on the important family economic behavior of leisure consumption, we can not only make up for the lack of neglecting the social class variables in the existing leisure consumption literature, but also expand the sociology research scope, and build a bridge between the social class connected with sociology and the leisure consumption in economics.

The structure of this paper is as follows: the second part describes and analyzes the sample data; the third part introduces the measurement model; the fourth part reports the empirical analysis results such as benchmark regression and the endogeneity discussion; and finally it is about the conclusion and policy recommendations.

\section{Statistics, Variables and Data Analysis}

1) Statistics

The data applied in this paper are from the micro household survey program named Chinese Family Panel Studies (CFPS) implemented by Institute of Social Science Survey (ISSS) of Peking University in 2016, which has investigated in details the economic situation, demographic characteristics and subjective attitudes of 45,319 residents in 14,763 households in China. This paper narrows down on the impact of social class on leisure consumption, in which demographic characteristics such as social class of residents mainly generate from the adult questionnaire data while economic characteristics such as leisure consumption are from the household questionnaire data. To achieve this, we matched the adult questionnaire data with the family questionnaire data according to the family code, and removed the samples with incomplete information. Eventually, we obtained the individual observation data of 35,051 respondents, which constitutes the samples analyzed in the current paper.

2) Variable

First, as for the structure of leisure consumption of the explained variable, we took the logarithm form of the total leisure consumption and travelling expenditure in the past year (ln_leisure_con) in the questionnaire as the explained variable. Secondly, as for the social class explained variables that we pay attention 
to, we choose the social status of residents in the local area as the explanatory variables reflecting the social stratum (social_stra) in the questionnaire. This variable is based on the score of the subjective evaluation by the interviewees. For the sake of comparison, the values are unified between 1 and 5 . The higher the score, the higher the social stratum of residents. We deleted the sample questionnaires without answers.

Thirdly, considering that the leisure consumption is also affected by other factors than social class, we selected a series of factors such as demographic characteristics of residents and family financial status as control variables referring to relevant literature [16] [17], in order to consider as many the heterogeneity characteristics of respondents as possible. In the demographic variables of residents, it mainly includes: whether the residents are males (genders), and when the residents are male, the value is 1 , otherwise 0 . The age of the residents should be counted as how the Western world counts their ages. Considering the possible nonlinear effects of age, we also set the square term of resident age (squ_age). If the residents are married, 1 will be taken for married or cohabiting residents, and 0 for the unmarried, divorced or widowed. The year of educational backgrounds (eduy) of residents is the number of years they have received education. If they have not received any formal education, the value is 0 . The education level to primary schools is 6 . The education level to junior high schools is 9. The education level of senior high schools is 12 . The education level of colleges is 15. The education level of Bachelor degrees is 16 . The education level of Master degrees and above is 19. In terms of whether residents are healthy (health) or whether they are registered in towns or cities (urban), if the answer is yes, the value is 1 , otherwise 0 . The number of family members (nfamily) is the number of permanent residents. When the profession of residents belongs to the Party or government departments/ people's organizations/army/public institutions, the assignment is 1 , and the rest is 0 . If the resident has an administrative/management position (manager), the value is 1 , otherwise 0 . If the resident is employed, 1 will be taken; otherwise 0 . If the resident often surfs on the Internet (netdummy), 1 will be taken, otherwise 0 will be taken. In the financial variables of households, income is the total income of households in the past year, with the unit of every 10,000 yuan. Asset (asset) is the market value of the current assets of the family, with the unit of every 10,000 yuan. Unlike household income and assets, many sample households have no debt, so the value is 0 when the household has no debt, otherwise it is 1 .

In addition, because of the symbolic nature of leisure consumption, it can reveal its social advantages and may play a role in Social stratification. Since the upper social class needs to maintain the status, or the lower class tends to narrow the gap between the upper class by imitating the consumption of the upper class, leisure consumption may have an impact on the social class, so the social class of residents may be endogenous in their leisure consumption. For this reason, this paper chooses the interviewee's interpersonal level as an instrumental variable (interpersonal). This variable is based on the scores of the respondents. For 
comparison, the values are all between 1 and 7 . The higher the score, the higher the level of hospitality of residents.

3) Data Analysis

Table 1 below demonstrates the descriptive statistical results of sample variables. The statistical results of 2016 samples showed that the logarithmic mean of leisure consumption was 8.2 ; half of the participants were male; the average age of residents was about $45 ; 76 \%$ of the residents were married; the average education period was 6 years; $67 \%$ of the residents were in good health conditions; $49 \%$ of the residents were registered as urban citizens; the average number of family members was $5 ; 2 \%$ of the residents have administrative or management positions; $65 \%$ of the residents were employed; $44 \%$ of the residents had access to Internet; the income, assets and liabilities of different families had huge gaps; the overall level of hospitality of residents was above the average.

\section{Measurement Model}

1) Basic Models

According to the continuous variable form of the logarithm of leisure consumption, we refer to the practice of scholars such as Treiman [18] and explore the impact of changes in the social status of residents on the percentage change in household leisure consumption while controlling various demographic and economic characteristics.

Table 1. Descriptive statistical results of variables.

\begin{tabular}{|c|c|c|c|c|}
\hline Variable & Mean & Standard Deviation & Minimum & Maximum \\
\hline ln_leisure_con & 8.20 & 1.54 & 1.61 & 13.13 \\
\hline social_stra & 2.79 & 1.07 & 1 & 5 \\
\hline gender & 0.50 & 0.50 & 0 & 1 \\
\hline age & 45.81 & 16.88 & 16 & 98 \\
\hline squ_age & 2383.23 & 1614.08 & 256 & 9604 \\
\hline married & 0.76 & 0.43 & 0 & 1 \\
\hline eduy & 6.38 & 5.03 & 0 & 19 \\
\hline health & 0.67 & 0.47 & 0 & 1 \\
\hline urban & 0.49 & 0.50 & 0 & 1 \\
\hline nfamily & 4.33 & 2.05 & 1 & 19 \\
\hline manager & 0.02 & 0.13 & 0 & 1 \\
\hline employed & 0.65 & 0.48 & 0 & 1 \\
\hline netdummy & 0.44 & 0.50 & 0 & 1 \\
\hline income & 6.30 & 12.90 & 0 & 833.60 \\
\hline asset & 41.04 & 180.84 & 0 & 10001 \\
\hline debts & 0.36 & 0.48 & 0 & 1 \\
\hline interpersonal & 5.82 & 1.14 & 1 & 7 \\
\hline
\end{tabular}


The OLS model set as follows:

$$
\text { ln_leisure_con }{ }_{i}=\beta_{0}+\beta_{1} \text { social_stra }_{i}+X_{i} \eta+\mu_{i}, \mu_{i} \sim N(0,1)
$$

Among them, ln_leisure_con refers to the logarithm of leisure consumption of the explained variable; social_stra is the explanatory variable of social class as the current focus; $X$ is the other control variable that affects leisure consumption. According to the previous theoretical analysis on the influence of social class on leisure consumption, we expected that the influence of social class on the logarithm of leisure consumption should be significantly positive.

2) Endogeneity

According to the previous discussion, the social class of residents may be endogenous in their leisure consumption. This means that the leisure consumption performance may affect the social stratum of residents. We chose the interviewee's hospitality as an instrumental variable, because groups with similar social strata usually have similar social experience and roles, and their speech manners and behaviors should be consistent with the etiquette and customs of their status (Bourdieu, 1984). The level of hospitality reflects the ability of interpersonal communication, which may have an essential impact on the consolidation and promotion of social stratum. This explains the level of hospitality (interpersonal) of instrumental variable is directly related to the social stratum (social_stra) of endogenous variable. However, the level of hospitality is not enough to change their leisure consumption, that is, the instrumental variable is not directly related to the explained variable. We also notice that instrumental variables can only affect the explained variables through the social class, that is, through the endogenous variables. In view of the above three criteria to determine whether the instrumental variable is suitable (the instrumental variable is directly related to the endogenous variable, or it is not directly related to the explained variable, or it can only affect the explained variable by influencing the endogenous variable), we provide the supporting test results below.

In consideration of the endogeneity of the residents' social class to their leisure consumption, we used the instrumental variable method to solve the endogeneity problem. The instrumental variable method is an effective method for solving endogenous problems. This method covers the 2SLS method. Its connotation is that when endogenous problems are generated by the endogenous variables and error terms in the model, according to relevant theories and data, find an explanation The proxy variables that are variable but not related to the random error term, that is, instrumental variables, and then the Hausman test is used to determine whether the instrumental variables are appropriate [19].

The 2SLS regression model is set as follows:

$$
\begin{aligned}
& \text { ln_leisure_con }{ }_{i}=\beta_{0}+\beta_{1} \text { }_{\text {ocial_stra }_{i}}+X_{i} \eta+\mu_{i}+\beta_{2} v_{i} \\
& \text { social_stra }_{i}=\pi_{0}+\pi_{1} \text { interpersonal }_{i}+v_{i}
\end{aligned}
$$

Model (2) consists of two stages: first, the social stratum (social_stra) of the endogenous explanatory variable regresses the hospitality level (interpersonal) of 
the instrumental variable, and second, the fitting value of the first stage is regressed by (ln_leisure_con). When the P value of the Hausman test is less than 0.05 , it is considered that there is an endogenous issue in the social stratum of the explanatory variable, and vice versa.

\section{Evidence Analysis}

This section discusses the impact of residents' social level on leisure consumption according to Model 1 and Model 2 defined in the previous section.

1) Benchmark Regression Results

Model (1) in Table 2 is based on the regression model without considering the possibility of endogeneity of heterogeneous Social stratification, and estimates the impact of Social stratification on leisure consumption in 2016. The control variables in the model include a series of variables such as demographic characteristics of residents and family financial status.

According to the regression results of Model (1), there is a significant positive correlation between residents' social class and leisure consumption: when residents' social class was higher, their leisure consumption level was also higher, which is consistent with our previous prediction. More specifically, for each level of improvement in the social class of residents, leisure consumption increased by 4.65 percentage. In addition to social class, most other factors also have a significant positive impact on their leisure consumption, including the age of residents, their marriage statuses, years of receiving education, registration status, family sizes, whether they have administrative or management positions, whether they have access to the Internet, income, assets, whether they are in debt. However, three factors have a significant negative impact on their leisure consumption: the genders of residents, the square item of age, and whether they are employed.

2) Endogeneity Test

Considering the endogenous possibility of the social class of residents to cultural consumption, Model (2) in Table 2 presented the regression results of instrumental variables considering the endogeneity. It can be seen from the regression results that the instrumental variable was significantly positive to the 2SLS regression coefficient of the explained variable. From the results of endogeneity test, the $\mathrm{P}$ value of Hausman test is less than 0.05 , which indicates that there exists endogeneity in social class, the setting of instrumental variables is reasonable, and the endogeneity issue is effectively solved. The regression results of instrumental variables show that the social class of residents has a significant positive impact on leisure consumption.

\section{Conclusions and Policy Implications}

It has become one of the important tasks of the Chinese government's macro-control on economy enhancing the cultural industries and improving living standards. The existing literature about impacts on leisure consumption mainly 
Table 2. Mechanism of leisure consumption.

\begin{tabular}{|c|c|c|}
\hline \multirow{2}{*}{ Explained Variables } & \multirow{2}{*}{$\begin{array}{c}\text { Model (1): OLS Regression } \\
\text { ln_leisure_con }\end{array}$} & \multirow{2}{*}{$\begin{array}{c}\text { Model (2): 2SLS Regression } \\
\text { ln_leisure_con }\end{array}$} \\
\hline & & \\
\hline \multirow[t]{2}{*}{ social_stra } & $0.0465^{\star * *}$ & $1.428^{\star *}$ \\
\hline & $(3.32)$ & $(3.28)$ \\
\hline \multirow[t]{2}{*}{ gender } & $-0.102^{\star * *}$ & -0.0109 \\
\hline & $(-3.63)$ & $(-0.23)$ \\
\hline \multirow[t]{2}{*}{ age } & $0.0254^{\star \star \star}$ & $0.0292^{\star \star *}$ \\
\hline & $(4.15)$ & $(3.49)$ \\
\hline \multirow[t]{2}{*}{ squ_age } & $-0.000161^{*}$ & $-0.000379^{* * *}$ \\
\hline & $(-2.57)$ & $(-3.48)$ \\
\hline \multirow[t]{2}{*}{ married } & -0.00298 & 0.00603 \\
\hline & $(-0.07)$ & $(0.10)$ \\
\hline \multirow[t]{2}{*}{ eduy } & $0.0391^{\star * \star}$ & $0.0337^{\star * *}$ \\
\hline & (12.81) & $(7.57)$ \\
\hline \multirow[t]{2}{*}{ health } & $0.0783^{*}$ & $-0.189^{*}$ \\
\hline & $(2.40)$ & $(-1.99)$ \\
\hline \multirow[t]{2}{*}{ urban } & $0.453^{* * *}$ & $0.670^{* * *}$ \\
\hline & $(14.32)$ & $(8.33)$ \\
\hline \multirow[t]{2}{*}{ nfamily } & $-0.0369^{* * *}$ & $-0.0578^{* * *}$ \\
\hline & $(-4.89)$ & $(-4.77)$ \\
\hline \multirow[t]{2}{*}{ manager } & $0.413^{\star * *}$ & 0.142 \\
\hline & $(4.97)$ & $(1.01)$ \\
\hline \multirow[t]{2}{*}{ employed } & -0.0493 & $-0.113^{\star}$ \\
\hline & $(-1.49)$ & $(-2.29)$ \\
\hline \multirow[t]{2}{*}{ netdummy } & $0.518^{\star * *}$ & $0.619^{\star * *}$ \\
\hline & (13.36) & $(10.11)$ \\
\hline \multirow[t]{2}{*}{ income } & $0.0118^{* * *}$ & $0.00866^{* * *}$ \\
\hline & $(14.12)$ & $(5.74)$ \\
\hline \multirow[t]{2}{*}{ asset } & $0.00358^{\star * *}$ & $0.00321^{\star * \star}$ \\
\hline & $(27.77)$ & $(15.34)$ \\
\hline \multirow[t]{2}{*}{ debts } & 0.00124 & -0.0109 \\
\hline & $(0.04)$ & $(-0.28)$ \\
\hline \multirow[t]{2}{*}{ _cons } & $4.875^{* * *}$ & 1.507 \\
\hline & $(34.83)$ & $(1.40)$ \\
\hline$N$ & 11754 & 11754 \\
\hline
\end{tabular}


focused on the economic characteristics and demographic characteristics (such as age, gender and the education level), yet often ignored the influence of Social stratification. Based on this, this paper may not only expand the relevant literature about Social stratification, but also supplement the leisure consumption literature.

The conclusion of this article is that the social class of residents had a significant positive impact on leisure consumption. One policy suggestion of this paper can be that the relevant departments should fully consider the possibility and complexity of the influence of the social class on the effectiveness of the policy when launching the relevant policy to the culture industries or leisure consumption.

\section{Conflicts of Interest}

The author declares no conflicts of interest regarding the publication of this paper.

\section{References}

[1] Throsby, D. (1999) Cultural Capital. Journal of Cultural Economics, 23, 3-12. https://doi.org/10.1023/A:1007543313370

[2] Guinn, R. (1980) Elderly Recreational Vehicle Tourists: Motivations for Leisure. Journal of Travel Research, 19, 9-12. https://doi.org/10.1177/004728758001900102

[3] Hawes, D. (1988) Travel-Related Lifestyle Profiles of Older Women. Journal of Travel Research, 27, 22-32. https://doi.org/10.1177/004728758802700204

[4] Zimmer, Z., Brayley, R.E. and Searle, M.S. (1995) Whether to Go and Where to Go: Identification of Important Influences on Seniors' Decisions to Travel. Journal of Travel Research, 33, 3-10. https://doi.org/10.1177/004728759503300302

[5] Weiss, Y. and Fershtman, C. (1998) Social Status and Economic Performance: A Survey. European Economic Review, 42, 801-820. https://doi.org/10.1016/S0014-2921(97)00137-2

[6] Auriol, E. and Renault, R. (2008) Status and Incentives. RAND Journal of Economics, 39, 305-326. https://doi.org/10.1111/j.1756-2171.2008.00015.x

[7] Noël, A. (2018) Race, Economics, and Social Status. U.S. Department of Labor, Bureau of Labor Statistics, Washington DC.

[8] Komori, T., Makinodan, M. and Kishimoto, T. (2019) Social Status and Modern-Type Depression: A Review. Brain and Behavior, 9, e01464. https://doi.org/10.1002/brb3.1464

[9] Cole, H., Mailath, J. and Postlewaite, A. (1998) Class Systems and the Enforcement of Social Norms. Journal of Public Economics, 70, 5-35. https://doi.org/10.1016/S0047-2727(98)00058-9

[10] Corneo, C. and Jeanne, O. (1999) Social Organization in an Endogenous Growth Model. International Economic Review, 40, 711-725. https://doi.org/10.1111/1468-2354.00036

[11] Chan, T. and Goldthorpe, J. (2007) Social Stratification and Cultural Consumption: Music in England. European Sociological Review, 23, 1-29. https://doi.org/10.1093/esr/jcl016

[12] Wang, Z., Jetten, J. and Steffens, K. (2019) The More You Have, the More You 
Want? Higher Social Class Predicts a Greater Desire for Wealth and Status. European Journal of Social Psychology. https://doi.org/10.1002/ejsp.2620

[13] Rauch, J.E. and Scoppa, V. (2015) Neckties in the Tropics: A Model of International Trade and Cultural Diversity. Canadian Journal of Economics, 42, 809-843. https://doi.org/10.1111/j.1540-5982.2009.01528.x

[14] Lu, C.-H. (2018) Social Status, Compulsory Education, and Growth. Economic Modelling, 68, 425-434. https://doi.org/10.1016/j.econmod.2017.08.013

[15] Kekäläinen, T., Wilska, T. and Kokko, K. (2018) Leisure Consumption and well-Being among Older Adults: Does Age or Life Situation Matter? Applied Research in Quality of Life, 12, 671-691. https://doi.org/10.1007/s11482-016-9483-6

[16] Bourdieu, F. (1984) Distinction: A Social Critique of the Judgment of Taste. Harvard University Press, Cambridge, MA.

[17] Zieba, M. (2016) Tourism Flows and the Demand for Regional and City Theatres in Austria. Journal of Cultural Economics, 40, 191-221.

https://doi.org/10.1007/s10824-015-9250-9

[18] Treiman, D.J. (2007) Industrialization and Social Stratification. Sociological Inquiry, 40, 207-234. https://doi.org/10.1111/j.1475-682X.1970.tb01009.x

[19] Hausman, J.A. (1987) Specification Tests in the Econometrics. Journal of the Econometric Society, 46, 1251-1271. https://doi.org/10.2307/1913827 